\title{
The menopausal syndrome
}

\author{
SONJA M. MCKINLAY AND MARGOT JEFFERYS \\ Department of Mathematics, Boston University, Massachusetts and \\ Department of Sociology, Bedford College, University of London
}

\section{SUMMARY}

Results of a postal questionnaire survey of 638 women aged 45 to 54 , living in the London area in 1964-65, indicate (consistently with other recent surveys) that hot flushes and night sweats are clearly associated with the onset of a natural menopause and that they occur in the majority of women. Hot flushes were reported to occur more frequently (usually daily) and over more of the body by women whose menstrual flow showed evidence of change or cessation, and for $25 \%$ of those women whose menses had ceased for at least one year, hot flushes persisted for five years or more. The other six symptoms specified, namely, headaches, dizzy spells, palpitations, sleeplessness, depression, and weight increase, showed no direct relationship to the menopause but tended to occur together, each being reported by approximately 30 to $50 \%$ of the respondents with little variation according to menopausal status. None of the six sociodemographic variables investigated, i.e., employment status, school leaving age, social class, domestic workload, marital status, and parity, had any marked association with the reported frequency of symptoms. The majority of respondents did not anticipate or experience any difficulties and only about $10 \%$ expressed regret at the cessation of menses. Despite embarrassment and/or discomfort from hot flushes, reported by nearly three-quarters of those experiencing this symptom, only one-fifth had apparently sought medical treatment.

\section{INTRODUCTION}

There is a widespread assumption that the period just before and just after the menopause (defined here as the last menstrual period) is one in which many normally symptom-free women experience a series of possibly distressing symptoms. There have been few studies, however, which have adequately investigated the correctness of this assumption. Most of the medical literature pertaining to the menopause reports case histories, gives clinical impressions or analyses data from selected unrepresentative samples of women under the care of gynaecologists and/or psychiatrists. Only four recent studies in western industrialized societies have been comparatively free from sampling biases and other methodological defects and have obtained data which permit the investigation of the relationship between the current prevalence of selfreported symptoms in middle-aged women and their menopausal status (Neugarten and Kraines, 1965; Prill, 1966; Jaszmann, van Lith, and Zaat, 1969; Thompson, Hart, and Durno, 1973). The first two surveys showed that psychosomatic and psychological complaints were not reported more frequently by so-called 'menopausal' than by younger women. The third survey similarly showed that, except perhaps for fatigue, headaches, and irritability, such symptoms were not clearly associated with the menopause. The fourth survey presents a rare attempt to replicate an earlier study, in that the sampling method, definitions, and questionnaire employed followed closely those used in collection of the data for the study reported here.

Apart from these studies, only four earlier reports appear to have explicitly questioned the existence of a large commonly occurring group of 'menopausal' symptoms (Campbell, 1937; Greenhill, 1946; Stern and Prados, 1946; Donovan, 1951). Of these, only Stern and Prados, and Greenhill included substantial empirical evidence for the conclusion (common to all four reports) that a marked 'menopausal syndrome' of mainly psychological disorders occurs in only a small proportion of women.

With few exceptions there appear to have been few attempts to study the inter-relationships among symptoms themselves or the possible relationship between symptoms and various sociodemographic factors (Jaszmann et al., 1969 and Thompson et al., 1973). Three reports suggested that psychosomatic and psychological complaints were associated 
directly. with vasomotor symptoms (usually defined as flushing and/or sweating) rather than with the menopause itself (Hannan, 1927; Novak, 1940; Hoskins, 1944). Only the first, however, provided evidence for this observation.

This paper presents an attempt, in a sample drawn from a 'well' population of women, to (a) investigate possible interrelationships among a selection of reported symptoms, both physiological and psychosomatic; $(b)$ explore possible associations between the reported occurrence of symptoms and various sociodemographic characteristics; (c) determine the extent to which reported symptoms are actually associated with the menopause itself; and (d) elicit attitudes to the cessation of menses and to the occurrence of hot flushes, including in the latter case the extent to which medical treatment was sought.

\section{Sampling, Definitions, and Method}

A detailed description of the method of sampling and the response rate has been given in a previous paper which reported the median age at menopause (estimated at 50.78 years) and the association of this age with various pre-existing social and biological variables (McKinlay, Jefferys, and Thompson, 1972). The data relate to 638 women aged 45 to 54 inclusive who had experienced or were at risk to a natural menopause, whose names were drawn in January 1965 from the age-sex registers kept by eight general practice units located in or near London, and who responded to a postal precoded questionnaire.

In the earlier paper three categories of menopausal status were distinguished as follows:

1. premenopausal-menstruated within the last three months

2. menopausal-last menstruated between three and 12 months ago

3. postmenopausal-not menstruated within the last 12 months

For this study, finer distinctions were required if symptoms were to be related more closely in time to the menopause. The following categories, which correspond closely to those used by Jaszmann et al. (1969), were used to distinguish menopausal status:

A. regular menses-menstruated in the last three months, with no change in regularity or volume in the previous year

B. transitional-menstruated within the last three months, but with some change in regularity and/or volume in the previous year
C. menopausal-last menstruated between three and 12 months ago

D. postmenopausal-divided into eight groups as follows:

1. menstruated last between 1 and 2 years ago

2. menstruated last between 2 and 3 years ago

3. menstruated last between 3 and 4 years ago

4. menstruated last between 4 and 5 years ago

5. menstruated last between 5 and 6 years ago

6. menstruated last between 6 and 7 years ago

7. menstruated last between 7 and 9 years ago

8. menstruated last more than 9 years ago.

As the eight postmenopausal groupings require information regarding the age at last menses, which is subject to considerable memory error in reporting (MacMahon and Worcester, 1966; McKinlay et al., 1972), this detailed classification should be considered with some caution in the analysis.

To investigate the relationships among symptoms, as well as the relationship between symptoms and sociodemographic factors, a method of clustering suggested by Kerridge (1969) and also used by Thompson et al. (1973) was employed in the preliminary analysis to transform each of the pair-wise correlation coefficients between variables into a distance between two-dimensional points, each of which represents a variable. The distance between points provides a measure of the association between the variables: when shown graphically, the closer the two points, the more closely associated are the two corresponding variables. In other words, the distances between points on the resulting graph are measures of the relative strength of association between pairs of variables, and only have meaning in relation to each other. The scale of these distances is, therefore, arbitrary and has been omitted from Figure 1. Of course, this graph merely indicates possible interrelationships among variables, which still require detailed investigation and explanation.

\section{ANALYSIS}

The results of the preliminary cluster analysis are presented in Fig. 1, each point representing one of the 16 variables included. Details of these variables, and the measurements or scores used for each, are presented in Table I.

Three general relationships are discernible from this graph. First, with the exception of age, the points representing the six sociodemographic variables included form a loose cluster, at considerable distance from the remaining points. This would imply that, in this sample of women, none of these 
Employment status
- Pority
- Domestic worklood

Marital status

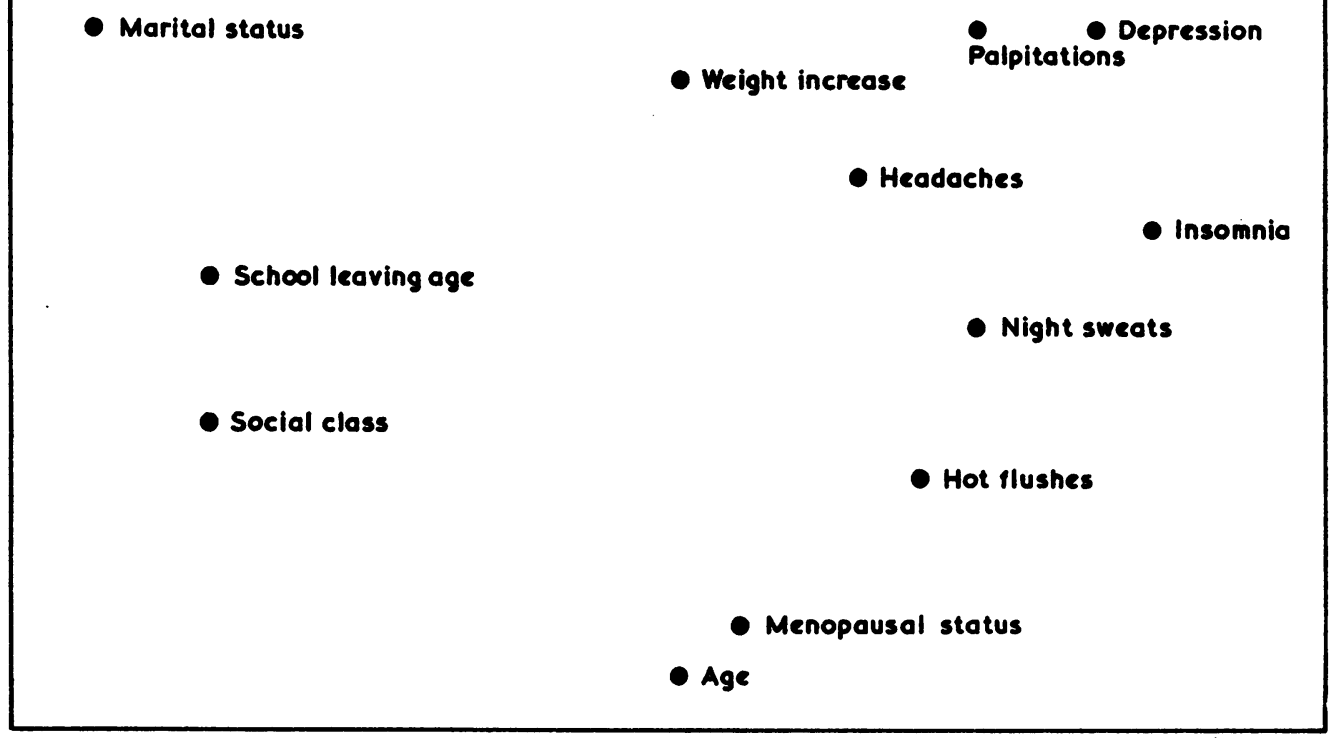

FIG. 1. Results of a cluster analysis of the relationships between the menopause, symptoms and sociodemographic characteristics for 614 women at risk to a natural menopause, aged $45-54$ inclusive.

characteristics was closely associated with either menopausal status (employing the trichotomous definition used in the first paper) or the symptoms included. Various cross-tabulations of these factors subsequently confirmed this general lack of association, apart from the slight differences in menopausal age by parity and social class noted in the previous paper (McKinlay et al., 1972). Second, the very small distance between the points representing age and menopausal status indicates a close association between these variables, as would be expected $a$ priori. Third, from the graph it appears that the only symptom directly associated with menopausal status is hot flushing. The remaining symptoms appear to be associated rather with each other in a loose cluster of points, relatively distant from that representing menopausal status.

\section{REPORTING OF SYMPTOMS}

Table II gives the proportion of each menopausal status group which reported experiencing each of eight symptoms at some time during the previous year. Excluding hot flushes, the reported frequencies lie, with few exceptions, between 30 and $50 \%$ for all groups, depression being more frequently reported. Only hot flushes and night sweats appear to reach any clear peak in frequency in the menopausal group (C), increasing from about $20 \%$ among premenopausal women to a maximum of 75 and $58 \%$ respectively, and tapering off to less than $30 \%$ among women who are at least nine years postmenopausal.

There is evidence of an increase in sleeplessness, depression, weight increase, and palpitations from the regularly menstruating to the transitional groups, and for the latter two symptoms only, a decrease in women at least nine years postmenopausal. For none of these symptoms, however, is there any clear peak or marked variation.

Figure 2 plots the mean number of symptoms reported in a year by each menopausal group, both when hot flushes and night sweats are included in 
TABLE I ANALYSIS, WITH DETAILS OF MEASUREMENT

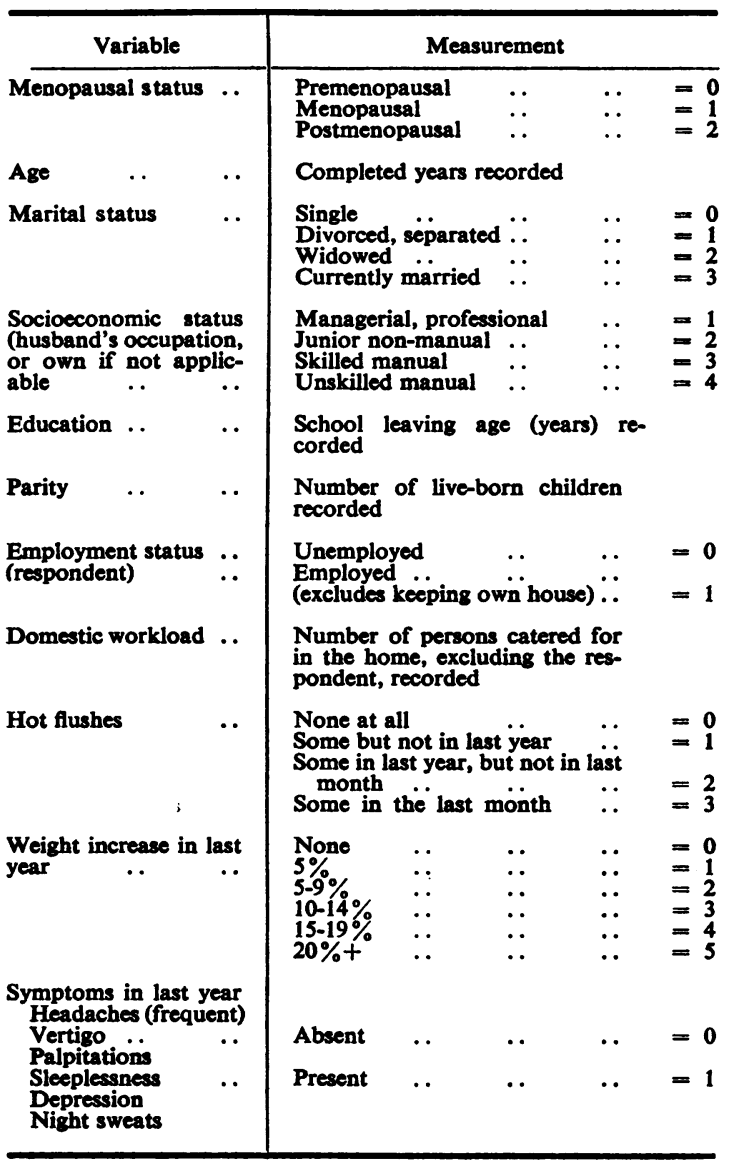

DESCRIPTION OF VARIABLES INCLUDED IN THE CLUSTER

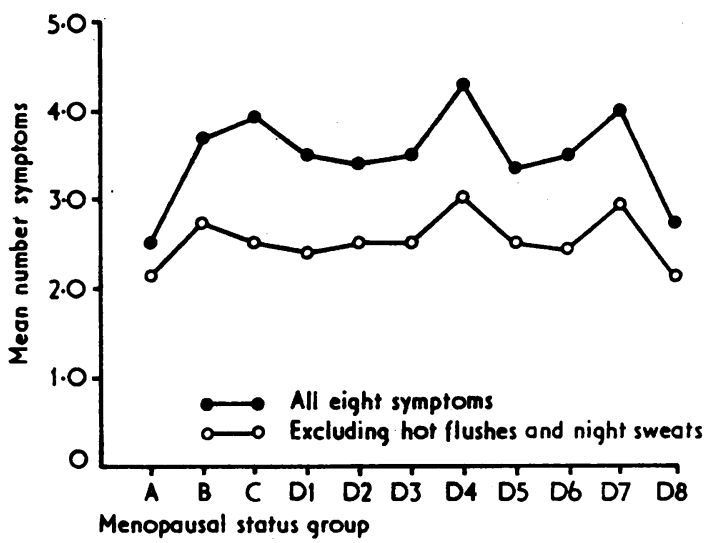

Fig. 2. Mean number of symptoms experienced within each menopausal group, with and without hot flushes and night sweats.

the symptom list and when they are not. Although subject to considerable variation, the plot indicates that the time immediately before and up to nine years after the menopause is associated with a generally higher rate of reported symptoms than earlier or later periods. The high means for groups D4 and D7, which appear to be due to symptoms other than hot flushes or night sweats, may be artefacts of faulty recall. They may reflect the tendency to 'round off' the reported year of the last menstrual period, discussed in our previous paper (McKinlay et al., 1972).

\section{HOT FLUSHES}

It appears from the data summarized in Fig. 3 that hot flushing occurred relatively rarely among

TABLE II

PERCENTAGE OF EACH MENOPAUSAL STATUS GROUP REPORTING EACH OF EIGHT SYMPTOMS IN THE LAST YEAR

\begin{tabular}{|c|c|c|c|c|c|c|c|c|c|c|c|c|c|}
\hline \multirow{2}{*}{\multicolumn{2}{|c|}{ Symptom }} & \multicolumn{11}{|c|}{ Menopausal Status Group* } & \multirow[b]{2}{*}{ Total } \\
\hline & & $\mathbf{A}$ & $\mathbf{B}$ & $\mathbf{C}$ & D1 & D2 & D3 & D4 & D5 & D6 & D7 & D8 & \\
\hline Hot flushes .. & .. & $17 \cdot 9$ & $44 \cdot 3$ & $75 \cdot 0$ & $62 \cdot 3$ & $54 \cdot 5$ & $65 \cdot 5$ & $67 \cdot 6$ & $48 \cdot 0$ & $64 \cdot 0$ & $64 \cdot 5$ & $28 \cdot 6$ & $49 \cdot 8$ \\
\hline Night sweats & .. & $21 \cdot 6$ & $45 \cdot 4$ & $58 \cdot 3$ & $43 \cdot 5$ & $39 \cdot 4$ & $41 \cdot 4$ & $51 \cdot 4$ & $36 \cdot 0$ & $48 \cdot 0$ & $48 \cdot 4$ & $28 \cdot 6$ & $40 \cdot 8$ \\
\hline Headaches .. & .. & $45 \cdot 5$ & $46 \cdot 6$ & $38 \cdot 3$ & $31 \cdot 9$ & $39 \cdot 4$ & $31 \cdot 0$ & $40 \cdot 5$ & $44 \cdot 0$ & $36 \cdot 0$ & $38 \cdot 7$ & $28 \cdot 6$ & $40 \cdot 8$ \\
\hline Dizzy spells .. & .. & $23 \cdot 1$ & $42 \cdot 5$ & $30 \cdot 0$ & $33 \cdot 3$ & $39 \cdot 4$ & $34 \cdot 5$ & $29 \cdot 7$ & $28 \cdot 0$ & $24 \cdot 0$ & $38 \cdot 7$ & $23 \cdot 8$ & $35 \cdot 0$ \\
\hline Palpitations .. & .. & $31 \cdot 3$ & $40 \cdot 2$ & $38 \cdot 3$ & $39 \cdot 1$ & $42 \cdot 4$ & $37 \cdot 9$ & $54 \cdot 1$ & $24 \cdot 0$ & $32 \cdot 0$ & $38 \cdot 7$ & $28 \cdot 6$ & $35 \cdot 0$ \\
\hline Sleeplessness & .. & $20 \cdot 9$ & $39 \cdot 4$ & $45 \cdot 0$ & $37 \cdot 7$ & $39 \cdot 4$ & $34 \cdot 5$ & $51 \cdot 4$ & $32 \cdot 0$ & $32 \cdot 0$ & $58 \cdot 1$ & $47 \cdot 6$ & $36 \cdot 0$ \\
\hline Depression .. & .. & $38 \cdot 8$ & $55 \cdot 7$ & 55.0 & $42 \cdot 0$ & $48 \cdot 5$ & $44 \cdot 8$ & $59 \cdot 5$ & $56 \cdot 0$ & $56 \cdot 0$ & $61 \cdot 3$ & $52 \cdot 4$ & $50 \cdot 1$ \\
\hline Weight increase & .. & $38 \cdot 8$ & $48 \cdot 9$ & $50 \cdot 0$ & $53 \cdot 6$ & $42 \cdot 4$ & $58 \cdot 6$ & $67 \cdot 6$ & $48 \cdot 0$ & $60 \cdot 0$ & $49 \cdot 6$ & $33 \cdot 3$ & $47 \cdot 5$ \\
\hline No symptoms & .. & $16 \cdot 4$ & $6 \cdot 6$ & $5 \cdot 0$ & $8 \cdot 7$ & $6 \cdot 1$ & $3 \cdot 4$ & $2 \cdot 7$ & $8 \cdot 0$ & $4 \cdot 0$ & $3 \cdot 2$ & $23 \cdot 8$ & $8 \cdot 6$ \\
\hline Total $(=100 \%)$ & . & 134 & 174 & 60 & 69 & 33 & 29 & 37 & 25 & 25 & 31 & 21 & 638 \\
\hline
\end{tabular}

* See text for definition of Menopausal Status Groups, as used in Tables II to V and Figures 2 and 3. 


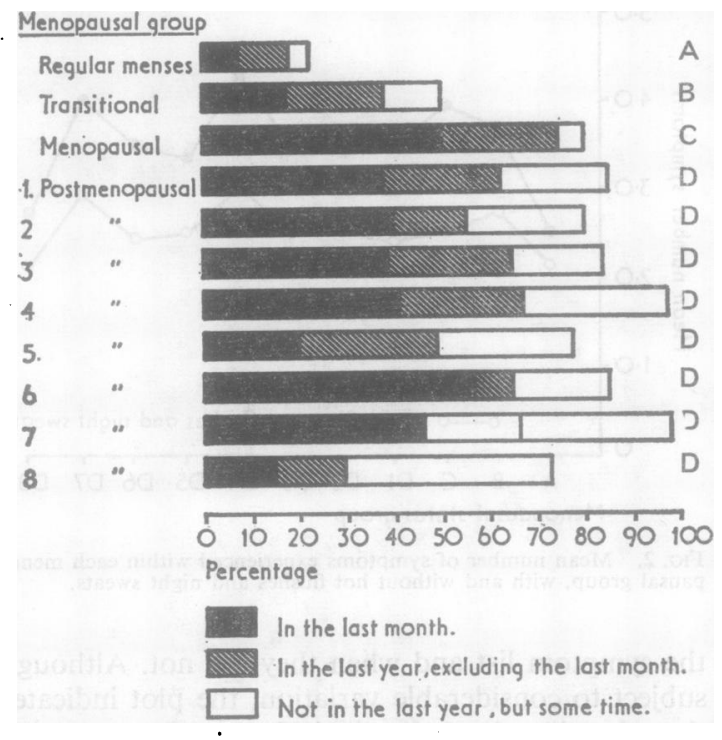

Fio. 3. Percentage of women in each menopausal status group experiencing hot flushes, within three time periods.

women who had experienced no change in the last year in the regularity of their menstrual cycle or in the volume of blood lost during the menses (group A). By contrast, four out of five of the menopausal group (C) had experienced hot flushing at some time, three quarters of them in the year prior to the survey. Moreover, although a peak appears to be reached in this menopausal group, the majority ( $f$ postmenopausal women continued to experience some flushing and most of them reported it as occurring in the last month. Only among those whose menopause had reportedly taken place at least nine years previously was there a substantially smaller proportion reporting flushes in the current year: but, even in this group, three in every 10 reported the occurrence of the symptom in this period.

Evidence that hot flushes are experienced by most women over a period of years is summarized in Table III. Of the 85 women whose menopause had taken place at least five years previously (groups D5 to D8 inclusive) and who had had flushes at some time, $82 \%$ reportedly experienced them for over one year and $26 \%$ for five or more years. Moreover, for seven out of 10 of these women, hot flushing at its greatest intensity had occurred at least once a day and generally more frequently.

Those who had experienced hot flushes were also asked whether they had felt the sensation on the face and neck only or all over their bodies. Of those who were still menstruating regularly and who had
TABLE III

SYMPTOM DURATION AND MAXIMUM FREQUENCY FOR THOSE WHO REPORTED EVER HAVING HOT FLUSHES

\begin{tabular}{|c|c|c|c|c|c|c|}
\hline \multicolumn{2}{|c|}{$\begin{array}{l}\text { Menopausal } \\
\text { Status Group }\end{array}$} & \multicolumn{2}{|c|}{$\begin{array}{l}\text { Duration } \\
(>1 \mathrm{yr})\end{array}$} & \multicolumn{2}{|c|}{$\begin{array}{l}\text { Max. Frequency } \\
\text { (Daily) }\end{array}$} & \multirow{2}{*}{$\begin{array}{l}\text { Total ever } \\
\text { had Hot } \\
\text { Flushes }\end{array}$} \\
\hline & & No. & $\%$ & No. & $\%$ & \\
\hline $\begin{array}{l}\text { A } \\
\text { B } \\
\text { C } \\
\text { D1 } \\
\text { D2 } \\
\text { D3 } \\
\text { D4 } \\
\text { D5 } \\
\text { D6 } \\
\text { D7 } \\
\text { D8 }\end{array}$ & $\begin{array}{l}. . \\
\because . \\
\because . \\
\because \\
\because \\
\therefore \\
\therefore \\
.\end{array}$ & $\begin{array}{l}11 \\
31 \\
20 \\
46 \\
17 \\
19 \\
24 \\
13 \\
17 \\
28 \\
12\end{array}$ & $\begin{array}{l}39 \cdot 3 \\
36 \cdot 5 \\
41 \cdot 7 \\
79 \cdot 3 \\
70 \cdot 8 \\
79 \cdot 2 \\
68 \cdot 6 \\
68 \cdot 4 \\
81 \cdot 0 \\
93 \cdot 3 \\
80 \cdot 0\end{array}$ & $\begin{array}{r}8 \\
51 \\
42 \\
44 \\
17 \\
20 \\
27 \\
13 \\
15 \\
23 \\
9\end{array}$ & $\begin{array}{l}28 \cdot 6 \\
60 \cdot 0 \\
87 \cdot 5 \\
75 \cdot 9 \\
70 \cdot 8 \\
83 \cdot 3 \\
77 \cdot 1 \\
68 \cdot 4 \\
71 \cdot 4 \\
76 \cdot 7 \\
60 \cdot 0\end{array}$ & $\begin{array}{l}28 \\
85 \\
48 \\
58 \\
24 \\
24 \\
35 \\
19 \\
21 \\
30 \\
15\end{array}$ \\
\hline
\end{tabular}

had hot flushes (admittedly a very small number), most reported that the sensation was confined to their face and neck. Those whom we have described as transitional and menopausal generally reported that flushing covered their whole body. Those who were some years postmenopausal were more likely to say that only the face and neck were involved or, in contrast to the premenopausal, that the site of the flushing varied. Insofar as a whole body sensation implies greater intensity, it would seem that those who were approaching their last menstrual period were likely to experience the most intense sensation of flushing.

The relationship between flushing and the remaining eight symptoms is summarized in Table IV. The most noteworthy trend is in the percentage reporting night sweats. Few women reported experiencing night sweats in the past year without also reporting hot flushes. Such a relationship between these two symptoms was indicated in the cluster analysis. Except in a few instances, the remaining six symptoms were also reported more frequently by those who had had hot flushes than by those who had not, consistent with the loose clustering shown in Figure 1.

\section{Treatment and Attrtudes}

A self-completed precoded questionnaire is not in general a good instrument for obtaining reliable information about attitudes. However, depending on menopausal status, respondents were asked first, whether they thought they would be (or were) relieved, sorry or no different when they no longer had periods, and, second, whether they thought the change of life (menopause) would be (or had been) a difficult time for them. In addition, all the women who had experienced hot flushes were asked to say whether they had felt embarrassed, acute physical discomfort, both or neither. 
TABLE IV

PERCENTAGE OF EACH MENOPAUSAL STATUS GROUP REPORTING SYMPTOMS BY REPORTED PRESENCE OR ABSENCE OF HOT FLUSHES IN PREVIOUS YEAR

\begin{tabular}{|c|c|c|c|c|c|c|c|c|c|c|c|c|c|}
\hline & & \multicolumn{10}{|c|}{ Menopausal Status Group } & & \\
\hline \multirow{2}{*}{\multicolumn{2}{|c|}{ Symptom }} & \multicolumn{2}{|c|}{$\mathbf{A}$} & \multicolumn{2}{|c|}{$\mathbf{B}$} & \multicolumn{2}{|c|}{$\mathbf{C}$} & \multicolumn{2}{|c|}{ D1-D4 } & \multicolumn{2}{|c|}{ D5-D8 } & \multicolumn{2}{|c|}{ Total } \\
\hline & & $+\mathbf{H F}$ & - HF* $^{*}$ & $+\mathbf{H F}$ & $-\mathbf{H F}$ & $+\mathbf{H F}$ & $-\mathbf{H F}$ & $+\mathbf{H F}$ & $-\mathbf{H F}$ & $+\mathbf{H F}$ & $-\mathbf{H F}$ & $+\mathbf{H F}$ & $-\mathbf{H F}$ \\
\hline $\begin{array}{ll}\text { Night sweats } & \ldots \\
\text { Headaches } & \ldots \\
\text { Dizzy spells } & \ldots \\
\text { Palpitations } & \ldots \\
\text { Sleeplessness } & \ldots \\
\text { Depression } & . \\
\text { Weight increase }\end{array}$ & $\begin{array}{l}. . \\
\ddot{.} \\
\ddot{0} \\
\ddot{.}\end{array}$ & $\begin{array}{l}45 \cdot 2 \\
62 \cdot 5 \\
50 \cdot 0 \\
50 \cdot 0 \\
37 \cdot 5 \\
37 \cdot 5 \\
54 \cdot 2\end{array}$ & $\begin{array}{l}16 \cdot 4 \\
41 \cdot 8 \\
17 \cdot 3 \\
27 \cdot 3 \\
17 \cdot 3 \\
39 \cdot 1 \\
14 \cdot 5\end{array}$ & $\begin{array}{l}62 \cdot 8 \\
50 \cdot 6 \\
54 \cdot 5 \\
42 \cdot 9 \\
40 \cdot 3 \\
57 \cdot 1 \\
58 \cdot 4\end{array}$ & $\begin{array}{l}26 \cdot 8 \\
43 \cdot 3 \\
33 \cdot 0 \\
38 \cdot 1 \\
45 \cdot 4 \\
54 \cdot 6 \\
41 \cdot 2\end{array}$ & $\begin{array}{l}68 \cdot 9 \\
37 \cdot 8 \\
31 \cdot 1 \\
40 \cdot 0 \\
46 \cdot 7 \\
57 \cdot 8 \\
57 \cdot 8\end{array}$ & $\begin{array}{l}26 \cdot 7 \\
40 \cdot 0 \\
36 \cdot 7 \\
33 \cdot 3 \\
40 \cdot 0 \\
46 \cdot 7 \\
26 \cdot 7\end{array}$ & $\begin{array}{l}65 \cdot 7 \\
41 \cdot 9 \\
41 \cdot 0 \\
50 \cdot 5 \\
47 \cdot 6 \\
60 \cdot 0 \\
61 \cdot 9\end{array}$ & $\begin{array}{l}4 \cdot 8 \\
28 \cdot 8 \\
22 \cdot 2 \\
30 \cdot 2 \\
28 \cdot 6 \\
27 \cdot 0 \\
41 \cdot 3\end{array}$ & $\begin{array}{l}66 \cdot 7 \\
22.6 \\
40.7 \\
44.4 \\
48.1 \\
55.6 \\
55.6\end{array}$ & $\begin{array}{l}12 \cdot 5 \\
16 \cdot 7 \\
16 \cdot 7 \\
8 \cdot 3 \\
37 \cdot 5 \\
58 \cdot 3 \\
41 \cdot 7\end{array}$ & $\begin{array}{l}65 \cdot 6 \\
45 \cdot 2 \\
43 \cdot 7 \\
45 \cdot 9 \\
40 \cdot 3 \\
58 \cdot 4 \\
55 \cdot 4\end{array}$ & $\begin{array}{l}17 \cdot 7 \\
37 \cdot 2 \\
23 \cdot 4 \\
27 \cdot 0 \\
28 \cdot 5 \\
44 \cdot 4 \\
31 \cdot 8\end{array}$ \\
\hline Total $(=100 \%$ & . & 24 & 110 & 77 & 97 & 45 & 15 & 105 & 63 & 54 & 48 & 305 & 333 \\
\hline
\end{tabular}

Table V shows the proportion of women responding with different answers to the two attitudinal questions concerning the cessation of periods. Only a small proportion of those who had menstruated within the last year said they would feel sorry when they no longer had periods and an even smaller proportion of those who had had the menopause indicated regret. A rather larger proportion of women who had menstruated in the last year anticipated that the change of life (menopause) would be difficult, and nearly one-third of those who were postmenopausal said it had been difficult for them. Some of those who said they had experienced difficulties gave some written details on their questionnaire, and most of these comments indicated that they had experienced both physical and emotional discomfort.

Just under one half $(48.5 \%)$ of all those who had ever had hot flushes said they felt acute physical discomfort, with or without embarrassment. An additional $20.5 \%$ had felt embarrassment but not acute physical discomfort. Yet scarcely more than

TABLE V

PERCENTAGE DISTRIBUTION OF TWO MEASURES OF ATIITUDES TO THE MENOPAUSE FOR TWO MENOPAUSAL STATUS GROUPS

\begin{tabular}{|c|c|c|c|c|c|c|}
\hline & & & \multicolumn{4}{|c|}{ Menopausal Status Group } \\
\hline & & & \multicolumn{2}{|c|}{ A-C } & \multicolumn{2}{|c|}{ D1-D8 } \\
\hline & & & \multicolumn{2}{|c|}{ 'Premenopausal' } & \multicolumn{2}{|c|}{ 'Postmenopausal' } \\
\hline & & & No. & $\%$ & No. & $\%$ \\
\hline \multicolumn{2}{|c|}{$\begin{array}{l}\text { Attitude } \\
\text { Relief } \\
\text { Regret } \quad \ldots \\
\text { No different or mixed } \\
\text { No answer } \\
\text { Difficulty anticipated }\end{array}$} & $\begin{array}{l}. . \\
\cdots \\
\cdots\end{array}$ & $\begin{array}{r}164 \\
49 \\
138 \\
17\end{array}$ & $\begin{array}{r}44 \cdot 6 \\
13 \cdot 3 \\
37 \cdot 5 \\
4 \cdot 6\end{array}$ & $\begin{array}{r}109 \\
25 \\
128 \\
8\end{array}$ & $\begin{array}{r}40 \cdot 4 \\
9 \cdot 3 \\
47.4 \\
3 \cdot 0\end{array}$ \\
\hline $\begin{array}{l}\text { No } \because \\
\text { Yes answer }\end{array}$ & $\begin{array}{l}. . \\
\cdots\end{array}$ & $\because$ & $\begin{array}{r}284 \\
68 \\
16\end{array}$ & $\begin{array}{r}77 \cdot 2 \\
18 \cdot 5 \\
4 \cdot 3\end{array}$ & $\begin{array}{r}186 \\
80 \\
4\end{array}$ & $\begin{array}{r}68 \cdot 9 \\
29 \cdot 6 \\
1 \cdot 5\end{array}$ \\
\hline Total .. & .. & $\cdots$ & 368 & $100 \cdot 0$ & 270 & $100 \cdot 0$ \\
\hline
\end{tabular}

one in five $(21.9 \%)$ of the total reporting hot flushes had sought medical treatment for them. Not surprisingly, those who experienced both acute physical discomfort and embarrassment were most likely to consult a doctor (46.7\% of them did), and those who experienced neither sensation least likely $(11 \%)$.

It has sometimes been suggested that working class women are more likely than middle class women to welcome the menopause because it means they are no longer at risk to an unwanted pregnancy, the assumption being that the former are less capable of preventing conception. At the same time it is sometimes suggested that working class women, being less sophisticated and with fewer opportunities for self-indulgence, are more likely to 'take the menopause in their stride' as a 'natural event' and therefore less likely to anticipate or experience difficulties (Neugarten, Wood, Kraines, and Loonis, 1963).

It was possible to throw some light on both these hypotheses. There was no support for the first suggestion. Women who left school at 14 (most of whom would be daughters and wives of manual workers) were no more and no less likely than those who left school at $\mathbf{1 5}$ or later to welcome the cessation of periods. Consistent with the second hypothesis, early school leavers were rather less likely to anticipate or experience difficulties during the 'change of life'. However, those in both groups who had hot flushes did not differ significantly with regard to feelings of embarrassment and discomfort. In short, there was little support in this admittedly limited survey of attitudes for the hypothesis that different social classes differ consistently in their attitude to the menopause and to hot flushing. Nor did the data lend support to the hypothesis that women of differing marital status and parity have different attitudes in this respoect. 


\section{Discussion}

Before attempting to interpret the results of this survey, two important related points should be emphasized.

First, the data consist of self-reported symptoms which were specified in the questionnaire but may have been subject to varying interpretation by the respondents. Moreover, because the symptoms (with the exception of weight increase) are subjectively experienced sensations, they cannot be independently verified; nor did the conditions of the enquiry allow for testing the reliability of reporting. In particular, some women may have distinguished flushing from sweating and reported one or both, while others may have included both symptoms under 'flushes' or 'sweats'. Even in the available literature, flushes and sweats appear to have been considered as one symptom (for example, Hannan, 1927; Greenhill, 1946). Inconsistencies in reporting have also been noted between interviews with the same women (Donovan, 1951) and between different women with the same disorder (Blahey, 1969).

Second, although an opportunity was provided for respondents to list further symptoms, it was seldom used, and reporting was effectively restricted to those symptoms specified in the questionnaire. There is, in this method of presentation, a problem of suggestion, in that an affirmative may be given to a listed symptom which, if it had not been listed, might not have been mentioned. In other words, this method of data gathering is likely to lead to overreporting of the specified set of symptoms and underreporting of others, thus creating bias in the estimates of prevalence.

This limitation in the study design may have contributed to the rather high proportions reporting each of the symptoms. However, the four other studies of 'well' women, which used other datacollecting methods, also reported high rates for many symptoms in somewhat larger symptom lists (Medical Women's Federation, 1933, Neugarten and Kraines, 1965; Jaszmann et al., 1969; Thompson et al., 1973). The earliest of these three studies had the lowest rates, but since it relied on retrospective information it is likely to be the least reliable. Neugarten and Kraines included 28 symptoms and reported very high rates for most of them in both young women (between 13 and 44 years) and older women, presumably at risk to a natural menopause (self-defined). They also had comparable results with those reported here for flushes and sweats. The former symptom was reported by $68 \%$ of the 'menopausal' women and by less than $30 \%$ of the remainder, while corresponding percentages for sweating were $32 \%$ and less than $20 \%$. Peaks of
$65 \%$ and $40 \%$ were reported for hot flushes and perspiration, respectively by Jaszmann et al.-also consistent with the present and other reported rates. Thompson and her co-workers also found generally high symptom rates, most of them being reported by at least $20 \%$ of the women. Hot flushes were reported by $74 \%$ of the postmenopausal women and only one woman reported night sweats without flushing.

Earlier studies also reported that flushing, closely followed by sweating, were the symptoms most clearly associated with the menopause (Hannan, 1927; McDowell and Paterson, 1940; Rogers, 1956; Newton and Odom, 1964), and when percentage rates were given, the prevalence of hot flushes was consistently estimated at about $70 \%$.

The finding in the present study, that night sweats usually occur along with hot flushes (also noted by Hannan (1927) and confirmed by Thompson et al. (1973)), deserves further investigation. It may be that these symptoms are not distinct, night sweats being merely a night-time manifestation of hot flushing.

The remaining symptoms considered in thiso survey do not appear to be related to the menopause directly, although all were more commonly reportedo by women in the transitional menopausal or immediate postmenopausal phase than by those who were still menstruating normally or those whose menopause occurred at least nine years ago. These results are consistent with those reported by Neugarten and Kraines (1965). Jaszmann et al. (1969) showed that tingling extremities, headaches, and irritability also reached a peak in reported rates at the time of the menopause, followed by a sharp decline; but further investigation of these symptoms is needed.

Hot flushes, the only symptom clearly and directly associated with the menopause, not only lasted for some years in many women but also tended to occur daily, on face and neck alone or on the whole body. Similar descriptions were reported by both Hannan (1927) and Thompson et al. (1973).

The findings concerning attitudes and treatment are also of interest. Few women had had medical advice or treatment for hot flushes, despite the discomfort and embarrassment which such symptoms often caused. This finding is consistent with that of Newton and Odom (1964), who found that only $23 \%$ of 80 postmenopausal American women consulted a physician concerning symptoms associated with the menopause. This contrasts with the findings of Thompson et al., who noted that, of the women who reported flushing, $45 \%$ received treatment, over double the proportion found in the 
present analysis. This difference could be due partly to the increased popularity of oestrogen treatment in the last few years, as well as to the policies of the particular general practice surveyed.

This survey suggested that the majority of women either saw the cessation of periods as presenting no change or as a relief. Few expressed regret at the change of life, although rather more anticipated or experienced difficulties during the change. A smallscale Israeli study undertaken in much greater depth indicated considerable anxiety about the change of physiological status (Maoz, Dowty, Antonovsky, and Wijsenbeek, 1970). Its findings, although tentative, suggest that cultural differences in respect of attitudes to reproduction and to the status of women in society may explain differences in the reports from Israel as compared with those from Britain and America.

We wish to thank Professor David Kerridge, Department of Statistics, University of Aberdeen, for the use of his cluster analysis program and computer time, and Professor John McKinlay, Boston University, for critical readings of earlier drafts.

\section{REFERENCES}

BlaHey, P. R. (1969). Double-blind and prolonged constant quinestrol therapy in the menopausal patient. Curr. ther. Res., 11, 755.

CAMPBell, C. H. (1937). Mental aspects of the menopause. J. Okla. med. Ass., 30, 12.

Donovan, J. C. (1951). The menopausal syndrome: a study of case histories. Amer. J. Obstet. Gynec., 62, 1281.

GreENHILl, M. H. (1946). A psychosomatic evaluation of the psychiatric and endocrinological factors in the menopause. Sth. med. J. (Bgham, Ala.), 39, 786.

Hannan, J. H. (1927). The Flushings of the Menopause. Baillière, Tindall and Cox, London.

Hoskrns, R. G. (1944). The psychological treatment of the menopause. J. clin. Endocr., 4, 605.

JaszmanN, L., Van Lith, N. D., and ZaAt, J. C. A. (1969). The perimenopausal symptoms. Med. Gynaec. Sociol., 4, 268.
KerRidGe, D. F. (1969). A program for two-dimensional clustering of variables. Personal communication. Aberdeen, Scotland.

MacMahon, B. and Worcester, J. (1966). Age at menopause: United States 1960-1962. U.S. Vital and Health Statistics, Series 11, Number 19. National Center for Health Statistics.

MaOz, B., DowTY, N., ANTonovsky, A., and WiJsenbeek, H. (1970). Female attitudes to menopause. Soc. Psychiat., 5, 35.

McDowell, J. G. and Paterson, A. S. (1940). The physical and psychological symptoms of the menopause. J. Obstet. Gynaec. Brit. Emp., 47, 319

MCKinlay, S., JefFerys, M., and Thompson, B. (1972). An investigation of the age at menopause. J. Biosoci. Sci., 4, 161.

MEdical Women's Federation (1933). An investigation of the menopause in one thousand women. Lancet, $1,106$.

Neugarten, B. L. and Kraines, R. J. (1965). “Menopausal symptoms" in women of various ages. Psychosom. Med., 27, 266.

-, WoOD, V., Kraines, R. J., and Loomis, B. (1963). Women's attitudes towards the menopause. Vita Humana (Basel), 6, 140.

Newton, M. and Odom, P. L. (1964). The menopause and its symptoms. Sth. med. J. (Bgham, Ala.). 57, 1309.

Novak, E. (1940). The management of the menopause. Amer. J. Obstet. Gynec., 40, 589.

PrILL, H. J. (1966). Die Beziehung von Erkrankungen und sozialpsychologischen Fakten zum Klimakterium. Med. Klin., 61, 1325.

Rogers, J. (1956). The menopause. New Engl. J. Med., 254, 697.

Stern, K. and Prados, M. (1946). Personality studies in menopausal women. Amer. J. Psychiat., 103, 358.

Thompson, B., Hart, S. A., and Durno, D. (1973). Menopausal age and symptomatology in a general practice. J. biosoc. Sci., 5, 71. 